\title{
Botryoisocoumarin A, a new COX-2 inhibitor from the mangrove Kandelia candel endophytic fungus Botryosphaeria sp. KcF6
}

\author{
Zhiran Ju${ }^{1,2,4}$, Xiuping Lin ${ }^{1,4}$, Xin $\mathrm{Lu}^{3}$, Zhengchao $\mathrm{Tu}^{3}$, Junfeng Wang ${ }^{1}$, Kumaravel Kaliyaperumal ${ }^{1}$, Juan Liu ${ }^{1}$, \\ Yongqi Tian ${ }^{1}$, Shihai $\mathrm{Xu}^{2}$ and Yonghong Liu ${ }^{1}$
}

The Journal of Antibiotics (2015) 68, 653-656; doi:10.1038/ja.2015.46; published online 13 May 2015

\begin{abstract}
Microorganisms belonging to a polyphyletic group of highly diverse organisms called endophytes reside primarily in plant hosts without causing any damage to their host. In many cases, these endophytes have played vital roles in the survival of their hosts by providing nutrients and producing abundant bioactive metabolites to protect the host against phytopathogenic bacteria. ${ }^{1,2}$ Mangrove plants, distributed in tropical and subtropical intertidal foreste wetlands, are biodiverse 'hotspots' that harbor a variety of endophytic fungi, ${ }^{3}$ which can potentially be a good source of novel bioactive compounds. ${ }^{4-6}$ Some of these secondary metabolites have shown various forms of biological activities such as antibacterial, ${ }^{7}$ cytotoxic, ${ }^{8}$ anti-inflammatory, ${ }^{9}$ antioxidant and anticancer. ${ }^{10}$ Therefore, in recent years, scientists have gradually begun to pay attention to these endophytes as promising targets for new clinical medicines. ${ }^{11}$ We have already reported a large number of new chemical constituents from mangrove-derived endophytic fungi. ${ }^{12-14}$ Many novel compounds such as alkaloids, ceramides, ${ }^{15}$ coumarins, ${ }^{16}$ polyketides, ${ }^{17}$ lactones, ${ }^{18}$ diterpenoids, ${ }^{19}$ benzofuran derivatives, ${ }^{20}$ meroterpenoids ${ }^{21}$ and polysaccharides ${ }^{22,23}$ have been reported from the genus Botryosphaeria. These compounds have exerted antibacterial, antioxidant, ${ }^{15}$ antifungal and cytotoxic activity. ${ }^{24}$ In the present study, we investigated the chemical constituents of the endophytic fungus Botryosphaeria sp. KcF6 derived from the mangrove plant Kandelia candel. A new mellein derivative, 3S-5, 8-dihydroxy-3-hydroxymethyldihydroisocoumarin, in addition to five other known compounds (2-6), was obtained (Figure 1). In this paper, the isolation, structure elucidation and biological activities of these compounds are reported.
\end{abstract}

The endophytic fungal strain KcF6 was isolated from the inner fruit part of the mangrove plant $K$. candel and grown on a solid-rice medium. The ethyl acetate (EtOAc) extract of the cultures was subjected to silica gel column chromatography, Sephadex LH-20 and semipreparative reversed-phase HPLC to obtain six metabolites (Figure 1). The structures of compounds 1-6 were determined using the extensive 1D, 2D-NMR and HRESIMS spectroscopic data and compared with the reported data. The absolute configuration of $\mathbf{1}$ was determined by CD spectra and X-ray crystallographic analysis.

Compound 1 was isolated as brown needle crystals. Its molecular formula was determined as $\mathrm{C}_{10} \mathrm{H}_{10} \mathrm{O}_{5}$ on the basis of the HRESIMS. The ${ }^{1} \mathrm{H}$ - and ${ }^{13} \mathrm{C}$-NMR data for $\mathbf{1}$ closely resembled with the data for mellein, ${ }^{25}$ the only difference being a hydroxymethyl group instead of a methyl group. The ${ }^{1} \mathrm{H}-\mathrm{NMR}$ displayed three methylene signals at $\delta_{\mathrm{H}}$ $2.82(\mathrm{dd}, J=17.0,12.0 \mathrm{~Hz}, \mathrm{H}-4 \mathrm{a}), \delta_{\mathrm{H}} 3.15$ (dd, $\left.J=17.0,3.5 \mathrm{~Hz}, \mathrm{H}-4 \mathrm{~b}\right)$ and $3.85(\mathrm{qd}, J=12.2,4.5 \mathrm{~Hz}, \mathrm{H}-9)$, a methyne signal at $\delta_{\mathrm{H}} 4.61$ $(\mathrm{m}, \mathrm{H}-3)$ and two ortho-coupled hydrogen protons at $\delta_{\mathrm{H}} 6.73$ $(\mathrm{d}, J=8.9 \mathrm{~Hz}, \mathrm{H}-6)$ and $\delta_{\mathrm{H}} 7.05(\mathrm{~d}, J=8.9 \mathrm{~Hz}, \mathrm{H}-7)$, respectively, which were assigned to a tetrasubstituted hydroquinone ring. This assignment was confirmed by the key HMBC correlations from $\mathrm{H}-9$ $\left(\delta_{\mathrm{H}} 3.85\right)$ to $\mathrm{C}-3\left(\delta_{\mathrm{C}} 80.1\right), \mathrm{C}-4\left(\delta_{\mathrm{C}} 22.6\right), \mathrm{H}-3\left(\delta_{\mathrm{H}} 4.61\right)$ to $\mathrm{C}-8 \mathrm{a}$ $\left(\delta_{\mathrm{C}} 124.2\right)$, and $\mathrm{H}-4\left(\delta_{\mathrm{H}} 2.82,3.15\right)$ to C-3 $\left(\delta_{\mathrm{C}} 80.1\right), \mathrm{C}-5 \mathrm{a}\left(\delta_{\mathrm{C}} 107.8\right)$, C-8a $\left(\delta_{\mathrm{C}} 124.2\right)$ and C-5 $\left(\delta_{\mathrm{C}} 145.7\right.$; Figure 2$)$. In the CD pattern of 1 (Figure 3), a negative Cotton effect for the $n-\pi^{\star}$ transition was observed at $\sim 260 \mathrm{~nm}$, which determined the $S$ configuration at C-3 on the basis of the similar CD profile of the 3-hydroxymethyl-8methoxydihydroisocoumarin. ${ }^{26}$ To verify the proposed structure, compound 1 was subjected to single crystal X-ray diffraction analysis (Figure 4). With five oxygen atoms in the molecule, the final refinement of the $\mathrm{Cu} \mathrm{K \alpha}$ data resulted in a Flack parameter of 0.0 (2) that determined the absolute stereochemistry at C-3 of 1 to be

\footnotetext{
${ }^{1}$ Key Laboratory of Tropical Marine Bio-resources and Ecology, Guangdong Key Laboratory of Marine Materia Medica, RNAM Center for Marine Microbiology, South China Sea Institute of Oceanology, Chinese Academy of Sciences, Guangzhou, China; ${ }^{2}$ Department of Chemistry, Jinan University, Guangzhou, China and ${ }^{3}$ Guangzhou Institutes of Biomedicine and Health, Chinese Academy of Sciences, Guangzhou, China

${ }^{4}$ These authors contributed equally to this work.

Correspondence: Dr S Xu, Department of Chemistry, Jinan University, Guangzhou 510632, China.

E-mail: txush@jnu.edu.cn

or Dr Y Liu, Key Laboratory of Tropical Marine Bio-resources and Ecology, Guangdong Key Laboratory of Marine Materia Medica, RNAM Center for Marine Microbiology, South China Sea Institute of Oceanology, Chinese Academy of Sciences, Guangzhou 510301, China.

E-mail: yonghongliu@scsio.ac.cn
}

Received 1 September 2014; revised 16 March 2015; accepted 25 March 2015; published online 13 May 2015 
<smiles>O=C[C@H]1Cc2c(O)ccc(O)c2C(=O)O1</smiles><smiles></smiles>

4
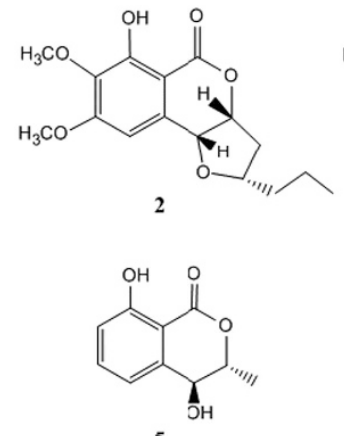<smiles>CCc1cc2c(O)cc(O)cc2c(=O)o1</smiles><smiles>COc1c(C)c(O)c(C)c2c1C(=O)OC2</smiles>

6
Figure 1 The structures of compounds 1-6.

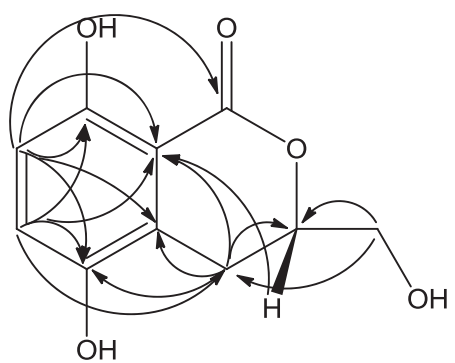

Figure 2 Key HMBC correlations for compound 1.

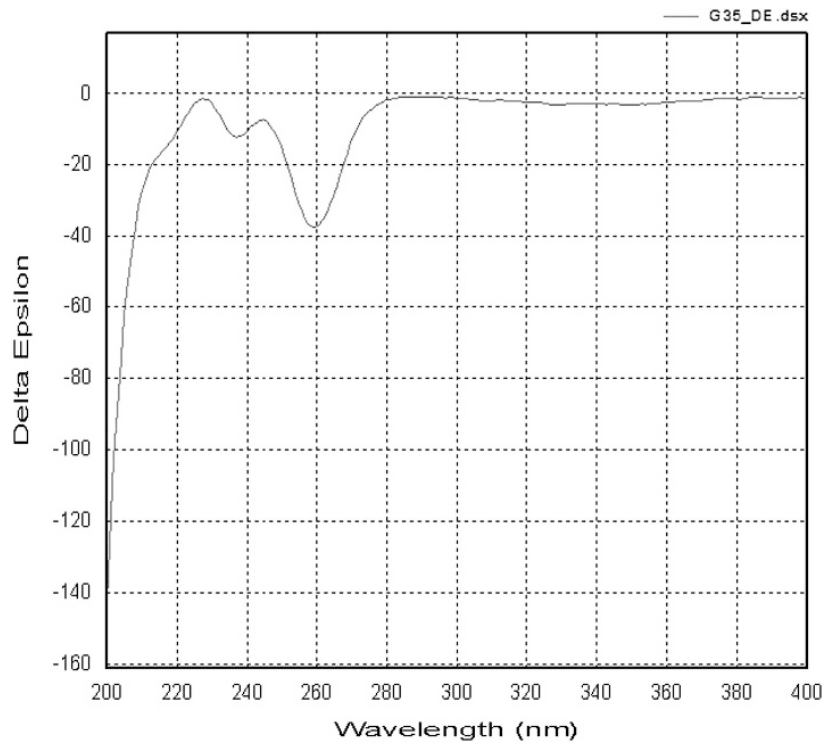

Figure 3 The CD spectrum of compound 1 . A full color version of this figure is available at The Journal of Antibiotics journal online.

S. Therefore, the structure was determined to be $3 S-5$, 8-dihydroxy-3-hydroxymethyldihydroisocoumarin and was named as botryoisocoumarin A.

In addition, five known compounds (2-6) were isolated and identified as monocerin (2), ${ }^{27}$ 3-methyl-6,8-dihydroxyisocoumarin (3), ${ }^{28}$ 8-methoxymellein (4), ${ }^{29}$ trans-4-hydroxymellein $(5)^{30}$ and 5-hydroxy-7-methoxy-4,6-dimethyl phthalide (6), ${ }^{31}$ by comparison of the spectroscopic data with the reported literature.

The isolated compounds were evaluated for their cytotoxic and antiinflammatory (COX-2) activities. Compound $\mathbf{1}$ exhibited significant

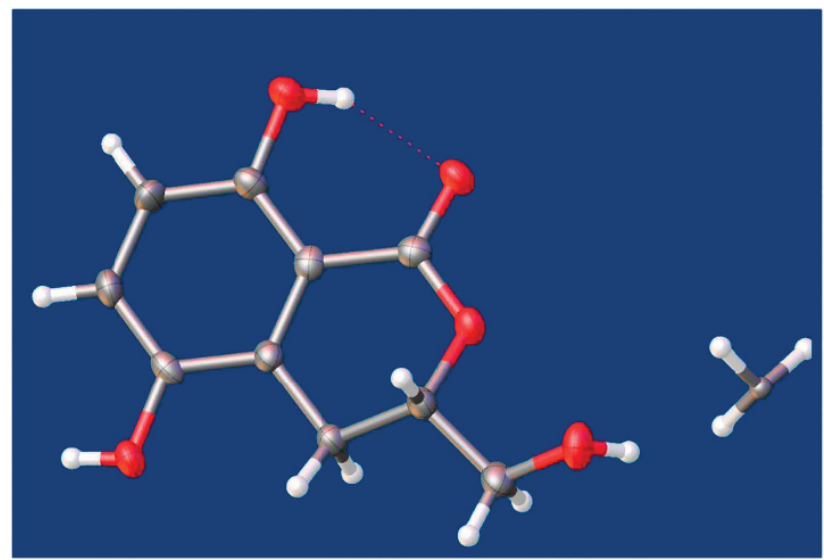

Figure 4 The X-ray structure of compound 1 .

Table $1{ }^{1} \mathrm{H},{ }^{13} \mathrm{C}-\mathrm{NMR}(500 / 125 \mathrm{MHz})$ and $\mathrm{HMBC}$ data for compound 1 in $\mathrm{CD}_{3} \mathrm{OD}$

\begin{tabular}{llrl}
\hline & \multicolumn{3}{c}{ Compound 1} \\
\cline { 2 - 4 } Position & $\delta_{H}(J$ in Hz $)$ & $\delta_{C}$ & $H M B C(H \rightarrow C)$ \\
\hline 1 & & 170.0 & \\
3 & $4.61, \mathrm{~m}$ & 80.1 & C-8a, C-9 \\
$4 \mathrm{a}$ & $2.82, \mathrm{dd}, 17.0,12.0$ & 22.6 & C-5, C-5a, C-8a, C-3, C-9 \\
$4 \mathrm{~b}$ & $3.15, \mathrm{dd}, 17.0,3.5$ & & C-5, C-5a, C-8a, C-3, C-9 \\
5 & & 145.7 & \\
$5 \mathrm{a}$ & & 107.8 & \\
6 & $7.05, \mathrm{~d}, 8.90$ & 123.8 & C-4, C-5, C-8, C-8a \\
7 & $6.73, \mathrm{~d}, 8.90$ & 115.1 & C-1, C-5, C-5a, C-8, C-8a \\
8 & & 154.9 & \\
$8 \mathrm{a}$ & & 124.2 & \\
9 & $3.85, \mathrm{qd}, 12.2,4.5$ & 63.1 & C-3, C-4 \\
\hline
\end{tabular}

COX-2 inhibitory activity with an $\mathrm{IC}_{50}$ value of $6.51 \mu \mathrm{m}$, whereas none of the compounds exhibited cytotoxicity on the tested cancer cell lines $\left(\mathrm{IC}_{50}>100 \mu \mathrm{M}\right)$.

\section{MATERIALS AND METHODS}

\section{General experimental procedures}

The NMR spectra were measured on a Bruker AC $500 \mathrm{MHz}$ NMR spectrometer (Bruker, Fällanden, Switzerland) with Tetramethylsilane (TMS) as an internal standard. High resolution mass spectra were recorded on a Bruker micro TOF-QII mass spectrometer (Bruker). CD spectra were measured with a Chirascan circular dichroism spectrometer (Applied Photophysics, Surrey, UK). Size exclusion chromatography was performed on Sephadex LH-20 gel (GE Healthcare, Uppsala, Sweden). Column chromatography was carried out on silica gel (200-300 $\mu \mathrm{m}$, Qingdao Marine Chemical Factory, Qingdao, China). Single-crystal X-ray diffraction data were measured on an Oxford Gemini S Ultra diffractometer. The TLC spots were detected under UV light or by heating after spraying with $5 \% \mathrm{H}_{2} \mathrm{SO}_{4}$ in $\mathrm{EtOH}$.

\section{Fungal strain}

The endophytic fungal strain KcF6 was isolated from the inner fruit part of a mangrove plant K. candel, which was collected at Daya Bay, Shenzhen, China, in March 2012, and grown on MB agar at $25^{\circ} \mathrm{C} . .^{17}$ This strain was stored on MB agar slants at $4{ }^{\circ} \mathrm{C}$ and then deposited at CAS Key Laboratory of Tropical Marine Bio-resources and Ecology, South China Sea Institute of Oceanology, Chinese Academy of Sciences, Guangzhou, China. The isolate was identified as a member of the genus Botryosphaeria on the basis of its ITS phylogenetic 
analyzes and was designated as Botryosphaeria sp. KcF6. The $489 \mathrm{bp}$ ITS sequence (NCBI Gen Bank accession number: KM 246294) has 99\% sequence identity to the B. dothidea strain CBS 116743 (NCBI Gen Bank accession number: AY786322).

\section{Fermentation, extraction and isolation}

Botryosphaeria sp. KcF6 was cultured on MB agar plates and incubated at $25^{\circ} \mathrm{C}$ for 7 days. Seed medium (potato: $200 \mathrm{~g}$; dextrose: $20 \mathrm{~g}$; sea salt: $10 \mathrm{~g}$; distilled water: $1000 \mathrm{ml}$ ) was inoculated with Botryosphaeria sp. KcF6 and incubated at $25^{\circ} \mathrm{C}$ for 2 days on a rotating shaker (180 r.p.m.). Rice medium in $1000 \mathrm{ml}$ flasks (rice: $200 \mathrm{~g}$; sea salt: $2.0 \mathrm{~g}$; distilled water: $200 \mathrm{ml}$ ) was inoculated with $10 \mathrm{ml}$ of seed solution and incubated statically at $25^{\circ} \mathrm{C}$ for 45 days.

The cultures obtained from 30 flasks were cut into small pieces, extracted with EtOAc $(6 \times 500 \mathrm{ml})$, sonicated, filtered and evaporated under vacuum at $40^{\circ} \mathrm{C}$ to yield $78 \mathrm{~g}$ of brown-colored crude extract. The EtOAc extract was subjected to silica gel column chromatography and eluted with petroleum ether/ $\mathrm{CH}_{2} \mathrm{Cl}_{2} \quad(90: 10 \rightarrow 0: 100)$, followed by $\mathrm{CH}_{2} \mathrm{Cl}_{2} / \mathrm{MeOH}(90: 10 \rightarrow 0: 100)$. Monitoring by TLC profiles, 6 fractions were obtained. Fraction 5 was applied to Sephadex LH-20 $\left(\mathrm{CHCl}_{3} / \mathrm{MeOH}, 1: 1\right)$ and further purified by silica gel column chromatography $\left(\mathrm{CHCl}_{3} / \mathrm{MeOH}, 20: 1\right)$ to give compounds $\mathbf{1}(15.6 \mathrm{mg})$ and $3(4.8 \mathrm{mg})$. Fraction 4 was applied to Sephadex LH-20 $\left(\mathrm{CHCl}_{3} / \mathrm{MeOH}, 1: 1\right)$ to give four subfractions. Fraction 4.3 was further purified by semipreparative reversed-phase HPLC to give compounds $5(5.6 \mathrm{mg})$ and $\mathbf{6}(6.3 \mathrm{mg})$. Fraction 3 was applied to Sephadex LH-20 $\left(\mathrm{CHCl}_{3} / \mathrm{MeOH}, 1: 1\right)$ to give three subfractions, Fraction 3.2 was further purified by semipreparative reversed-phase HPLC to give compound $2(5.4 \mathrm{mg})$, and fraction 3.3 was chromatographed on a silica gel column to give compound 4 ( $4.9 \mathrm{mg})$.

Botryoisocoumarin A (1): brown-colored needle crystals; UV (MeOH) $\lambda_{\max }$ : 329, 259, $237 \mathrm{~nm} ;{ }^{1} \mathrm{H},{ }^{13} \mathrm{C}-\mathrm{NMR}$ and HMBC data (see Table 1); HRESIMS, $211.0596[\mathrm{M}+\mathrm{H}]$ (calcd. for $\mathrm{C}_{10} \mathrm{H}_{11} \mathrm{O}_{5}, 211.0606$ ).

\section{X-ray crystallographic analysis of 1}

The crystals of compound $\mathbf{1}$ were grown in methanol at room temperature. The X-ray diffraction intensity data were collected on a CrysAlis PRO CCD area detector diffractometer with graphite monochromated $\mathrm{Cu} K \alpha$ radiation $(\lambda=1.54184 \AA)$ at $173 \mathrm{~K}$. The structure was solved using direct methods (SHELXL-97) and refined using full-matrix least squares difference Fourier techniques. All non-hydrogen atoms were refined anisotropically, and all hydrogen atoms were placed in idealized positions and refined as riding atoms with the relative isotropic parameters. Parameters in CIF format are available as an Electronic Supplementary Publication from Cambridge Crystallographic Data Centre (CCDC 1016389). These data can be obtained from: http://www. ccdc.cam.ac.uk/conts/retrieving.html.

X-ray crystallographic analysis of 1 : brown-colored crystal of $\mathrm{C}_{10} \mathrm{H}_{10} \mathrm{O}_{5}$, $\mathrm{M}=210.0829$, monoclinic, space group P $21, \mathrm{a}=4.6860$ (3) $\AA, \mathrm{b}=20.5218$ (14) $\AA, \quad c=5.8556(4) \AA, \quad V=552.07(7) \AA^{3}, \quad Z=2, \quad D_{\text {calc }}=1.457 \mathrm{~g} / \mathrm{mm}^{3}$, $\mathrm{F}(000)=256.0$, unique reflections: $1218\left(\mathrm{R}_{\text {int }}=0.0222, \mathrm{R}_{\text {sigma }}=0.0265\right)$ that were used in all calculations. Final $\mathrm{R}$ indicated $[I>2 \sigma(I)]: \mathrm{R}_{1}=0.0271(1200)$, $w R_{2}=0.0723(1218)$. A total of 1722 reflections were collected at $173 \mathrm{~K}$.

\section{Biological activity}

Cytotoxicity. All isolated compounds were evaluated against the ten human tumor cell lines (K562, MCF-7, A549, U937, HeLa, DU145, HL60, BGC823, MOLT-4 and H1975) according to Bergeron et al. ${ }^{32}$

\section{COX-2 inhibitory activity assay}

COX-2, as a well-established target, is an inducible enzyme in which expression is activated by cytokines, mitogens, endotoxins and tumor promoters. The antiinflammatory and analgesic properties of traditional NSAIDs are due primarily to the inhibition of COX-2. ${ }^{33}$ Hence, the isolated compounds were tested for COX-2 inhibitory activity using the COX (ovine) inhibitor screening kit according to the manufacturer's instructions. The test compounds were dissolved in DMSO, and the final concentration was set as $10 \mu \mathrm{m}$. The percentage inhibition has been calculated by comparison with control incubations.

\section{CONFLICT OF INTEREST}

The authors declare no conflict of interest.

\section{ACKNOWLEDGEMENTS}

This work was supported financially by the National Natural Science Foundation of China (Grant Nos. 41476135, 20902094, 41176148, 21002110, 21172094, 41376155 and 21202177).

1 Gunatilaka, A. A. L. Natural products from plant-associated microorganisms: distribution, structural diversity, bioactivity, and implications of their occurrence. J. Nat. Prod. $69,509-526(2006)$

2 Debbab, A. et al. Bioactive secondary metabolites from endophytes and associated marine derived fungi. Fungal Divers. 49, 1-12 (2011)

3 Shearer, C. A. et al. Fungal biodiversity in aquatic habitats. Biodivers. Conserv. 16, 49-67 (2007).

4 Aly, A. H. et al. Fungal endophytes from higher plants: a prolific source of phytochemicals and other bioactive natural products. Fungal Divers. 41 1-16 (2010).

5 Newman, D. J. \& Cragg, G. M. Natural products as sources of new drugs over the 30 Years from 1981 to 2010. J. Nat. Prod. 75, 311-335 (2012).

6 Aly, A. H. et al. Fungal endophytes: unique plant inhabitants with great promises. Appl. Microbiol. Biotechnol. 90, 1829-1845 (2011).

7 Maria, G. L. et al. Antimicrobial and enzyme activity of mangrove endophytic fungi of southwest coast of India. J. Agric. Technol. 1, 67-80 (2005).

$8 \mathrm{Li}, \mathrm{H}$. et al. Cytotoxic norsesquiterpene peroxides from the endophytic fungus Talaromyces flavus isolated from the mangrove plant Sonneratia apetala. J. Nat. Prod. 74, 1230-1235 (2011).

$9 \mathrm{Ai}, \mathrm{W}$. et al. Axinelline A, a new COX-2 inhibitor from Streptomyces axinellae SCSIO02208. Nat. Prod. Res. 28, 1219-1224 (2014).

10 Bhimba, B. V. et al. Anticancer and antimicrobial activity of mangrove derived fungi Hypocrea lixii VB1. Chin. J. Nat. Med. 10, 77-80 (2012).

11 Izumikawa, M. et al. Isolation of a novel macrocyclic dilactone-JBIR-101-from Promicromonospora sp RL26. J. Antibiot. 64, 689-691 (2011).

12 Bai, Z.-Q. et al. New phenyl derivatives from endophytic fungus Aspergillus flavipes AIL8 derived of mangrove plant Acanthus ilicifolius. Fitoterapia 95 194-202 (2014)

13 Sun, J.-F. et al. Pestalols A-E, new alkenyl phenol and benzaldehyde derivatives from endophytic fungus Pestalotiopsis sp AcBC2 isolated from the Chinese mangrove plant Aegiceras corniculatum. J. Antibiot. 67, 451-457 (2014).

14 Zhou, X. et al. A new aromatic amine from fungus Pestalotiopsis vaccinii. Phytochem. Lett. 7, 35-37 (2014).

15 Xiao, J. et al. Secondary metabolites from the endophytic Botryosphaeria dothidea of Melia azedarach and their antifungal, antibacterial, antioxidant, and cytotoxic activities. J. Agric. Food Chem. 62, 3584-3590 (2014).

$16 \mathrm{Xu}, \mathrm{Y}$. et al. A new 3,4-dihydroisocoumarin isolated from Botryosphaeria sp. F00741. Chem. Nat. Compd. 48, 205-207 (2012).

$17 \mathrm{Xu}, \mathrm{Y} .-\mathrm{H}$. et al. New polyketides isolated from Botryosphaeria australis strain ZJ12-1A. Helv. Chim. Acta 94, 897-902 (2011).

18 Rukachaisirikul, V. et al. Metabolites from the endophytic fungi Botryosphaeria rhodina PSU-M35 and PSU-M114. Tetrahedron 65, 10590-10595 (2009).

19 Yuan, L. et al. Labdane and tetranorlabdane diterpenoids from Botryosphaeria sp MHF, an endophytic fungus of Maytenus hookeri. Helv. Chim. Acta 92, 1118-1125 (2009).

20 Pongcharoen, W. et al. New dihydrobenzofuran derivative from the endophytic fungus Botryosphaeria mamane PSU-M76. Chem. Pharm. Bull. 55, 1404-1405 (2007).

21 Sassa, T. et al. Isolation and identification of new antifungal macrophorins E, F and G as malonyl meroterpenes from Botryosphaeria berengeriana. Biosci. Biotechnol. Biochem. 62, 2260-2262 (1998).

22 Giese, E. C. et al. Triple helix conformation of botryosphaeran, a $(1 \rightarrow 3 ; 1 \rightarrow 6)-\beta-D-$ glucan produced by Botryosphaeria rhodina MAMB-05. Carbohydr. Polym. 74, 953-956 (2008)

23 Vasconcelos, A. F. D. et al. Three exopolysaccharides of the beta-(1 -> 6)-D-glucan type and a beta-(1 -> 3:1 -> 6)-D-glucan produced by strains of Botryosphaeria rhodina isolated from rotting tropical fruit. Carbohydr. Res. 343, 2481-2485 (2008).

24 Abdou, R. et al. Botryorhodines A-D, antifungal and cytotoxic depsidones from Botryosphaeria rhodina, an endophyte of the medicinal plant Bidens pilosa. Phytochemistry 71, 110-116 (2010)

25 Oliveira, C. M. et al. Bioactive metabolites produced by Penicillium sp.1 and sp.2, two endophytes associated with Alibertia macrophylla (Rubiaceae). Z. Naturforsch. C. 64, 824-830 (2009)

26 Salvadori, P. et al. Anomalous face-selectivity in sharpless asymmetric dihydroxylation of O-allylbenzamides. J. Org. Chem. 61, 4190-4191 (1996).

27 Zhang, W. et al. Bioactive isocoumarins isolated from the endophytic fungus Microdochium bolleyi. J. Nat. Prod. 71, 1078-1081 (2008)

28 Singh, B. et al. Saccharonol B, a new cytotoxic methylated isocoumarin from Saccharomonospora azurea. Tetrahedron Lett. 54, 6695-6699 (2013).

29 Montenegro, T. G. C. et al. Cytotoxic activity of fungal strains isolated from the Ascidian Eudistoma vannamei. Chem. Biodivers. 9, 2203-2209 (2012). 
30 Yu, Z.-X. et al. Studies on chemical constituents in root of Phlomis medicinalis I. J. Chin. Mater. Med. 31, 656-658 (2006)

$31 \mathrm{Kjer}$, J. et al. Methods for isolation of marine-derived endophytic fungi and their bioactive secondary products. Nat. Protoc. 5, 479-490 (2010).
32 Bergeron, R. J. et al. Antineoplastic and antiherpetic activity of spermidine catecholamide iron chelators. Biochem. Biophys. Res. Commun. 121, 848-854 (1984).

33 Blobaum, A. L. et al. The 2'-trifluoromethyl analogue of indomethacin is a potent and selective COX-2 inhibitor. ACS Med. Chem. Lett. 4, 486-490 (2013).

Supplementary Information accompanies the paper on The Journal of Antibiotics website (http://www.nature.com/ja) 